\title{
CORRUPCIÓN EN EL PERÚ Y SU INCREMENTO EN EL MARCO DE LA EMERGENCIA SANITARIA DEL COVID-19
}

\section{CORRUPTION IN PERU AND ITS INCREASE IN THE CONTEXT OF THE HEALTH EMERGENCY OF COVID-19}

\author{
Karen Lizeth Alfaro-Mendives
}

\begin{abstract}
Resumen
El presente artículo tiene por objetivo evidenciar en qué medida los niveles de corrupción se han incrementado en el Perú durante el estado de emergencia sanitaria, declarada por el Gobierno mediante el Decreto Supremo N.․ 008-2020-SA del 11 de marzo de 2020, y sus modificatorias, a consecuencia del COVID-19. Si bien es cierto está demostrado que la corrupción hace daño a los paises, con mucha más razón, en tiempos de pandemia, donde el hambre y la pobreza apremian entre los más necesitados que, más que nunca, requieren de sus autoridades ayuda y una distribución justa de los recursos.

El enfoque es cualitativo, la técnica empleada ha sido la revisión documental y como instrumento se ha utilizado una matriz de análisis, donde se ha registrado los casos de corrupción suscitados durante la crisis sanitaria.

Se puede concluir que este problema de la corrupción va más allá de los valores, de la ética e integridad de las personas, pues ni cuestiones como la vida misma los detienen, para ello, se propone implantar mecanismos de lucha contra la corrupción externos que, si bien es cierto, no terminaran con el problema, pueden ser elementos disuasivos para que se frene de alguna manera con este flagelo.
\end{abstract}

\section{Palabras clave}

Corrupción; Gestión pública; Emergencia sanitaria; Estado de emergencia; Covid-19; Perú

\begin{abstract}
s
The purpose of this article is to show to what extent the levels of corruption have increased in Peru during the state of health emergency, declared by the government through Supreme Decree No. 008-2020-SA of March 11, 2020, and its amendments, as a result of COVID-19. While it is true, it has been demonstrated that corruption hurts countries, with much more reason, in times of pandemic, where hunger and poverty are pressing among the most needy who, more than ever, require their authorities to help and distribute fair of resources.

The approach is qualitative, the technique used has been the documentary review and an analysis matrix has been used as an instrument, where the cases of corruption raised during the health crisis have been recorded.

It can be concluded that this problem of corruption goes beyond the values, ethics and integrity of people, since neither issues such as life itself stop them, for this, it is proposed to implement external anti-corruption mechanisms that, Although it is true, they will not end the problem, they can be deterrents to stop it in some way with this scourge.
\end{abstract}

\section{Keywords}

Corruption; public management; health emergency; state of emergency; COVID-19; Peru

Clasificación JEL: D73 


\section{Introducción o estado del arte}

La corrupción siempre ha sido un fenómeno que ha impactado negativamente al desarrollo de los países con consecuencias nocivas en los ámbitos social, económico y político (Cartolano, 2009), principalmente en los países latinoamericanos (Morales, 2009; Rodríguez, 2011; Salinas, 2016; Albiac, 2011; Pastrana, 2019; Quiroz, 2020). Debido a su complejidad, ha sido muy estudiada desde sus diferentes aristas, se tienen estudios que lo abordan desde la perspectiva de la identificación de sus causas (Begovic 2005; Labaqui, 2017), otros lo tratan respecto a sus consecuencias (Zuleta, 2015; Artaza, 2019). Por otro lado, Picon y otros (2020) mencionan que la corrupción es uno de los fenómenos más estudiados, pero a su vez, más difíciles de analizar, no solamente por el anonimato de sus actores, sino también por la dificultad de su definición y la clasificación de las actividades como corruptas o no. Sin embargo, son pocos los trabajos que presentan alternativas de solución válidas para la lucha contra este gran flagelo, que si bien está demostrado hace daño a los países, con mucha más razón en tiempos de pandemia, donde el hambre, la enfermedad y la pobreza son las constantes entre los más necesitados que, hoy más que nunca, requieren de sus autoridades apoyo y ayuda.

Uno de los pocos trabajos que presenta propuestas para la situación problemática de la corrupción en el marco del COVID-19, es Madrid y Palomino (2020) quienes postulan la siguiente idea:

La implementación de programas de cumplimiento (compliance gubernamental) en sectores esenciales de la administración pública, que están especialmente expuestos a la realización de prácticas corruptas durante la atención de la pandemia de la
COVID-19, coadyuvará a reducir razonablemente el riesgo de corrupción o, en todo caso, a que aquel sea identificado y, posteriormente, informado a la autoridad competente, lo que comunicará, a cualquier futuro agente inclinado a abusar de su posición, de la existencia de protectores eficaces al interior de organizaciones públicas. (p.1)

Este tipo de propuestas se presentan, debido a que se observa en épocas de pandemia, que la corrupción va en ascenso y más bien se ha convertido en una oportunidad para que vaya en aumento. En Latinoamérica, la desconfianza ciudadana en sus democracias venía incrementándose, incluso, antes de la pandemia, por diferentes razones, como el incumplimiento de promesas electorales, las bajas condiciones de vida y los casos de corrupción en las más altas esferas gubernamentales, llegándose a denominar una "Sociedad de la desconfianza" (Quiroz, 2020).

Es importante precisar que, la pandemia por el coronavirus (COVID-19), declarada así por la Organización Mundial de la Salud, OMS, (2020), profundamente preocupada por los alarmantes niveles de propagación de la enfermedad y por su gravedad, y por los niveles también alarmantes de inacción, hizo necesario que los países en América Latina y el Caribe, al igual que en todo el mundo, tomen medidas de emergencia sanitaria, así como de aislamiento social. En ese sentido, generó que el Gobierno del Perú declare en emergencia sanitaria al territorio nacional por el plazo de noventa días, posteriormente ampliado por noventa días más², con el propósito de mitigar la propagación y contagio de esta nueva enfermedad, que viene ocasionado la muerte de miles de personas alrededor del mundo.

En este contexto, el Gobierno autorizó transferencias económicas, a través del Ministerio de Economía y Finanzas, a diversas

2 Mediante Decreto Supremo No 020-2020-SA, Decreto Supremo que prorroga la Emergencia Sanitaria declarada por Decreto Supremo Nº08-2020-SA 
instituciones públicas para la contratación directa, bajo la causal de situación de emergencia ${ }^{3}$, de bienes y servicios orientados a salvaguardar la salud y bienestar de los ciudadanos frente al brote de este virus, ya que se registraron muchos casos de corrupción nacionalmente, todos ellos vinculados al gasto público que se viene efectuando para atender la emergencia sanitaria (compra de equipos, mascarillas, entrega de bonos, canastas familiares, realización de pruebas rápidas, etc.). Sin embargo, esta situación ha sido aprovechada por algunos funcionarios y servidores públicos para cometer actos de corrupción en contra de la Administración Pública, lo que ha conllevado, principalmente, a poner en riesgo la salud de la población haciendo mal uso del poder para la obtención de beneficios personales (MINJUS, 2020).

Según Orellana (2020) la crisis sanitaria y económica mundial provocada por el COVID-19 es un fenómeno complejo, no lineal, cuyo abordaje debe realizarse mediante la transdisciplinariedad para darle respuesta a las principales interrogantes que hoy en día la humanidad se plantea al respecto. La corrupción se ha convertido en uno de los principales obstáculos para el crecimiento y está afectando tanto a los países en desarrollo como a las democracias consolidadas (Nieto, 2017) , con mucha más razón en épocas de pandemia, ya que se pierde dinero que es indispensable para enfrentar la crisis de manera efectiva, habiendo tanta necesidad de camas de unidad de cuidados intensivos (UCI), acondicionamiento de hospitales, instrumentos médicos, medicamentos, entre otros, que pueden servir para salvar vidas, existen ineficiencia del gasto público, con ello, viéndose afectada significativamente la gobernabilidad, la confianza de la ciudadanía ante sus autoridades y, sobretodo, desconfianza ante sus instituciones públicas.
Madrid y Palomino (2020) afirman que la corrupción es un fenómeno que ocasiona devastadoras consecuencias para la administración pública, pues socava su credibilidad y obstruye el cumplimiento de los fines que persiguen sus órganos e instituciones. Ello dificulta el acceso igualitario a bienes y servicios esenciales, y afecta, principalmente, la vida, la salud y otros importantes derechos de los ciudadanos en situación de pobreza y pobreza extrema, así como de quienes se encuentran en algún especial contexto de vulnerabilidad. Frías-Aceituno, Rodríguez-Domínguez \& García-Sánchez (2014) afirman que la corrupción suele venir asociada a la obtención de un beneficio propio y favorecida por la oportunidad que tienen los gestores, debido a la concentración de poder de decisión y actuación que poseen y la ausencia de riesgo de que tales acciones sean detectadas. Asimismo, es muy importante el estudio de las variables asociadas a la corrupción, siendo fundamental que tanto las instituciones públicas como privadas cuenten con información contrastada empíricamente para poder poner en marcha programas dedicados a reducir los niveles de corrupción imperantes en la sociedad (Julián $\&$ Bonavia, 2020).

Tal cual indican Márquez (2020); Gragera \& Pascual (2020); Picon, Ramos, Almanza y Ramos (2020) la corrupción daña a los países porque les quita la posibilidad de buscar el desarrollo y bienestar común, que se puede decir de aquellos funcionarios que aplican estas prácticas en un estado de emergencia como el que nos encontramos. Por lo tanto, las políticas más eficaces para los países, serán aquellas enfocadas al derecho fundamental que tienen los seres humanos para controlar el fruto de su trabajo, englobando de manera integral las libertades y derechos de producción, distribución o consumo de bienes y servicios. Por otro

3 Literal b) del numeral 27.1 del artículo $27^{\circ}$ del Texto Único Ordenado de la Ley N³0225, Ley de Contrataciones del Estado, aprobado por Decreto Supremo N082-2019-EF. 
lado, "se considera que es un grave obstáculo para el desarrollo económico porque eleva los costos de transacción, aumenta la incertidumbre y reduce la productividad" (Mikhail $\&$ Walter, 2015, p. 161).

Según Begovic (2005) los países con mucha corrupción no pueden esperar altas tasas de crecimiento que están directamente relacionadas con el emprendimiento empresario y la innovación. Pues el emprendimiento empresario se dirigirá a la actividad que le permita al emprendedor los mayores ingresos posibles en su actividad, por ende, los emprendedores, en lugar de centrarse en actividades productivas de generación de riqueza, se orientarán hacia la corrupción, redistribuyendo actividades y asignando sus talentos a eso. Como consecuencia, las innovaciones que son resultado del emprendimiento serán asignadas a la redistribución y la corrupción. En lugar de nuevos productos y nuevos métodos de producción, se presentarán nuevos métodos de corrupción.

Continuar con los hechos de corrupción en la pandemia, significa enquistar la corrupción institucional, esto puede multiplicarse hasta "Controlar prácticas corruptas y violar las reglas alejándose de su propósito" (Page, 2018).

Madrid \& Palomino (2020) mencionan que el compliance es el instrumento que reúne los dos planos (preventivo y reactivo) y permite a las personas jurídicas administrar sus riesgos y organizarse para cumplir todas sus obligaciones (legales y otras asumidas voluntariamente). Si aquel sistema de prevención está orientado a la mitigación de los riesgos legales que se derivan del incumplimiento de la normativa penal, se le denomina criminal compliance, y si está enfocado en el sector público, la ética pública o las buenas prácticas gubernamentales, se le llama compliance gubernamental.

Asimismo, es importante considerar también el caso de México, como otro caso de corrupción. Pérez (2020) dice que los co- rruptos no descansan, por lo tanto, el combate a este mal debe ser permanente. Durante la pandemia en México se han destapado casos de corrupción como la adquisición de insumos médicos a sobrecostos extremadamente exagerados; respiradores que duplicaban su precio entre los adquiridos en dependencias distintas con el mismo proveedor, las mismas condiciones y características de los materiales, pero distintos precios; la compra de materiales deficientes, como mascarillas, ropa quirúrgica, medicamentos, herramientas para que el personal de salud pudiera realizar sus tareas, entre otros.

En tiempo de crisis, se entiende que las decisiones se deben tomar bajo presión y en menor tiempo, por ello la ley contempla excepciones a los procedimientos de adquisiciones. Para ello, se omiten algunos pasos de los procesos de licitación, pero no se deben dejar de observar los principios de contratación, las normas para garantizar que el Estado realiza las mejores acciones, se puede observar que la urgencia de la crisis de salud, exhibe actos que no es encuentran apegados a la ley, que se vuelven discrecionales y que tiene que observarse con mucho cuidado para evitar la desviación de los recursos públicos para fines personales.

Lamentablemente, las extendidas incriminaciones de corrupción en los ámbitos políticos y gubernamentales generan una alterada e incierta realidad contemporánea conllevando a una crisis de credibilidad pública que afecta a los partidos políticos se ha instalado en la mayoría de las sociedades occidentales, lo que abre un vacío político en el que se muestra la falta de una instancia mediadora entre el nivel del individuo y el del Estado (Quiroga, 2018), aspecto que no es ajeno al Perú, donde ya no existe confianza en las instituciones públicas, sin dejar de mencionar que en los últimos años este país cuenta en su historia con cinco presidentes comprometidos con problemas de corrup- 
ción, aspecto que se esperaba iba a ser superado con el actual gobierno del presidente Martín Vizcarra Cornejo, sin embargo, con la emisión de los últimos videos y audios, esta esperanza ha quedado prácticamente descartada, siendo la situación bastante preocupante, sobre todo por el momento de pandemia que atravesamos.

La gestión pública ha sido denotada como una dimensión afectada por la corrupción, debido a que los ciudadanos desaprueban la gestión de gobierno nacional, regional y local y esto se debe a la falta de implantación de un sistema de control interno en el Perú que conlleva a que la corrupción avance y se convierta en una plaga mortal para el país (Albán \& Poma, 2019, p. 94).

Ya se sabe, que la corrupción desde una dimensión holística, trasciende esta perspectiva. Este fenómeno puede entenderse también desde una dimensión axiológica y sociocultural, es decir, desde los valores, y la representación, como hecho social total, como una práctica recurrente de entender el sentido relacional de las instituciones y personas, que trasciende las esferas del quehacer económico y jurídico normativo. (Yalle, 2020).

Como se puede observar este problema de la corrupción de los funcionarios públicos, va más allá de los valores, de la ética e integridad de las personas, pues ni cuestiones como la vida misma lo detienen, para ello se deben implementar mecanismos de lucha contra la corrupción externos que, si bien es cierto, no terminaran con el problema, al menos pueden ser elementos disuasivos para que se frene de alguna manera.

\section{Materiales y métodos}

El presente estudio es de enfoque cualitativo, la técnica empleada ha sido la revisión documental y como instrumento se ha utilizado una matriz analítica de registro.

La información procesada para el análisis y reflexión a efectos de evidenciar las posiciones vertidas en el presente estudio, tiene como fuente los casos en trámite registrados, hasta el 27 de julio del 2020, en la Procuraduría Pública Especializada en Delitos de Corrupción nacionalmente que se encuentran participando activamente en defensa de los intereses del Estado en más de 1186 casos que se originaron por presuntos actos de corrupción evidenciados durante esta crisis sanitaria.

\section{Análisis y resultados}

Resulta importante mencionar, que según MINJUS (2020) la defensa jurídica del Estado es la actividad de orden técnico legal que ejercen los procuradores públicos en atención a las disposiciones contenidas en el presente decreto legislativo, su reglamento y normas conexas, con la finalidad de aplicarlas en el ejercicio de sus funciones acorde con el ordenamiento jurídico vigente. Asimismo, la función del Procurador Público se encuentra enmarcada en la Constitución Política del Perú, que dispone que "la defensa de los intereses del Estado está a cargo de los procuradores Públicos, conforme a ley"4.

La información que se muestra a continuación, en función a la región, corresponde a los casos registrados por las sedes de la Procuraduría Pública Especializada en Delitos de Corrupción nacionalmente la misma que ejerce la defensa jurídica de los intereses del Estado en todo el territorio nacional ante instancias jurisdiccionales y no jurisdiccionales, en indagaciones policiales, investigaciones, procesos o procedimientos relacionados a la comisión de delitos de corrupción de funcionarios, en todas las moda-

$4 \quad$ Artículo 47 de la Constitución Política del Perú. 
lidades contempladas en las Secciones II, III y IV del Capítulo II del Título XVIII, del Libro Segundo del Código Penal ${ }^{5}$. Así también, coordina con las diferentes entidades públicas vinculadas con la prevención y lucha contra la corrupción, con la finalidad de ejercer una adecuada y eficiente defensa jurídica de los intereses del Estado, en su Boletín informativo 1: "Corrupción en la emergencia sanitaria COVID-19", que registra 1186 de presunta corrupción en este contexto de pandemia, detallada en la siguiente tabla:

Tabla 1. Número de casos de corrupción en el estado de emergencia al 27 de julio del 2020

\begin{tabular}{|c|c|c|c|c|}
\hline $\mathbf{N}^{\circ}$ & Sede & $\begin{array}{l}\text { Presentados } \\
\text { por La PPEDC }\end{array}$ & $\begin{array}{l}\text { Reportados por el } \\
\text { Ministerio Publico }\end{array}$ & Total de casos \\
\hline 1 & Ancash & 68 & 19 & 87 \\
\hline 2 & Junin & 85 & 0 & 85 \\
\hline 3 & La libertad & 7 & 70 & 77 \\
\hline 4 & Del santa & 70 & 1 & 71 \\
\hline 5 & Ayacucho & 53 & 12 & 65 \\
\hline 6 & Apurimac & 8 & 56 & 64 \\
\hline 7 & Moquegua & 16 & 39 & 55 \\
\hline 8 & Loreto & 9 & 44 & 53 \\
\hline 9 & Arequipa & 16 & 36 & 52 \\
\hline 10 & Madre de Dios & 3 & 49 & 52 \\
\hline 11 & Huanuco & 22 & 24 & 46 \\
\hline 12 & Cajamarca & 13 & 27 & 40 \\
\hline 13 & Lambayeque & 20 & 18 & 38 \\
\hline 14 & Puno & 17 & 21 & 38 \\
\hline 15 & Lima & 3 & 34 & 37 \\
\hline 16 & Lima norte & 0 & 32 & 32 \\
\hline 17 & Cusco & 30 & 0 & 30 \\
\hline 18 & Piura & 13 & 16 & 29 \\
\hline 19 & Callao & 12 & 16 & 28 \\
\hline 20 & Pasco & 24 & 3 & 27 \\
\hline 21 & Tacna & 6 & 21 & 27 \\
\hline 22 & Cañete & 0 & 22 & 22 \\
\hline 23 & Ucayali & 10 & 8 & 18 \\
\hline 24 & Huaura & 8 & 9 & 17 \\
\hline 25 & Huancavelica & 8 & 6 & 14 \\
\hline 26 & Ica & 10 & 4 & 14 \\
\hline 27 & San martin & 0 & 13 & 13 \\
\hline 28 & Sullana & 8 & 4 & 12 \\
\hline
\end{tabular}

5 Artículo 46 del Reglamento del Decreto Legislativo № 1326, "Decreto Legislativo que restructura el Sistema Administrativo de Defensa Jurídica del Estado y crea la Procuraduría General del Estado". 


\begin{tabular}{|c|l|c|c|c|}
\hline 29 & Moyobamba & 0 & 10 & 10 \\
\hline 30 & Bagua & 1 & 8 & 9 \\
\hline 31 & Tumbes & 5 & 3 & 9 \\
\hline 32 & Lima sur & 5 & 6 & 8 \\
\hline 33 & Amazonas & 0 & 0 & 6 \\
\hline 34 & Yurimagas & 1 & 0 & 0 \\
\hline 35 & Atalaya & 0 & 0 & 0 \\
\hline 36 & Chincha & 0 & 635 & 1186 \\
\hline
\end{tabular}

Fuente: MINJUS. Procuraduría Pública Especializada en Delitos de Corrupción (2020).

Como se puede advertir, el 51\% del total de casos se concentra en siete regiones, estas son: Ancash, Lima, Arequipa, La Libertad, Junín, Ayacucho y Cajamarca.

Así, en el marco de su competencia constitucional ${ }^{6}$, la PPEDC ha presentado, hasta el momento 264 denuncias ante las fiscalías especializadas en delitos de corrupción del Ministerio Público nacionalmente. Los casos, en su mayoría, están asociados a las contrataciones públicas como, por ejemplo, compras de implementos de bioseguridad, equipos médicos, productos de limpieza y aseo personal, servicios de alimentación, etc.

En lo que se refiere a las entidades agraviadas, se observa que:

Tabla 2. Porcentaje de casos de corrupción por institución agraviada en estado de emergencia al 27 de julio del 2020

\begin{tabular}{|l|c|c|}
\hline \multicolumn{1}{|c|}{ INSTITUCIÓN AGRAVIADA } & CASOS & $\%$ \\
\hline Municipalidad distrital & 322 & $44.1 \%$ \\
\hline Municipalidad provincial & 128 & $17.5 \%$ \\
\hline Gobierno Regional & 126 & $17.3 \%$ \\
\hline PNP & $88.1 \%$ \\
\hline Ministerio de Salud & 20 & $2.7 \%$ \\
\hline Ministerio del Interior & 9 & $1.2 \%$ \\
\hline Essalud & 7 & $1.0 \%$ \\
\hline Ministerio de Defensa & 3 & $0.4 \%$ \\
\hline Ministerio de Justicia & 3 & $0.4 \%$ \\
\hline Poder Judicial & 3 & $0.4 \%$ \\
\hline Ministerio Público & 3 & $0.4 \%$ \\
\hline Otros & 18 & $2.5 \%$ \\
\hline
\end{tabular}

Fuente: Minjus. Procuraduría Pública Especializada en Delitos de Corrupción (2020).

6 El artículo 47 de la Constitución Política del Perú dispone que "la defensa de los intereses del Estado está a cargo de los procuradores Públicos, conforme a ley". 
Figura 1. Porcentaje de casos de corrupción por institución agraviada en estado de emergencia al 27 de julio del 2020

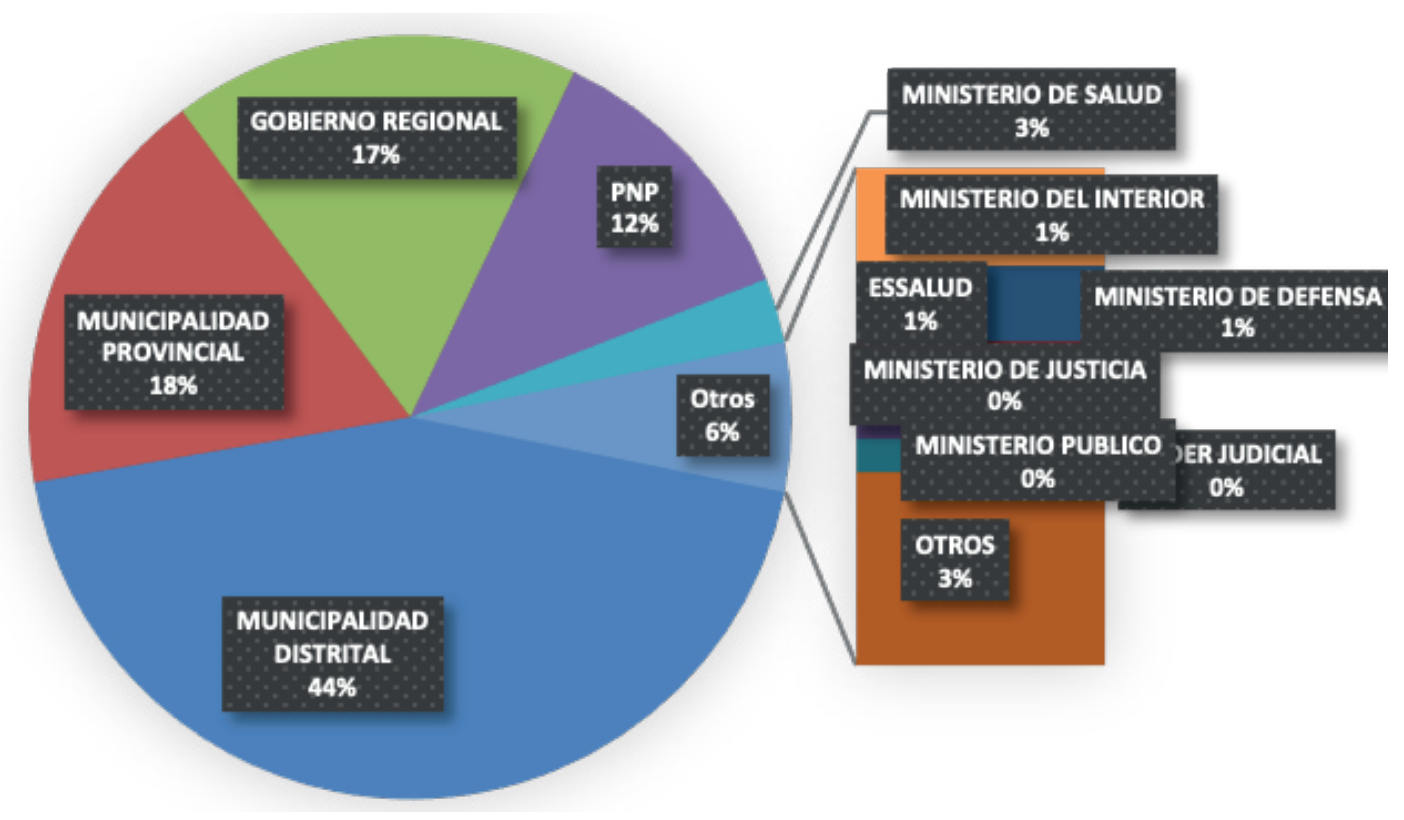

En lo que se refiere al tipo de delito:

Tabla 3. Porcentaje de casos de corrupción por tipo de delito al 27 de julio del 2020

\begin{tabular}{|l|c|c|}
\hline \multicolumn{1}{|c|}{ DELITO } & CANTIDAD DE CASOS & $\%$ \\
\hline Peculado & 134 & $26.9 \%$ \\
\hline Colusion & 79 & $18.4 \%$ \\
\hline Negociacion incompatible & 54 & $2.0 \%$ \\
\hline Cohecho & 6 & $1.7 \%$ \\
\hline Malversacion de fondos & 5 & $1.7 \%$ \\
\hline Omision de funciones & 5 & $0.7 \%$ \\
\hline Trafico de influencias & 2 & $0.3 \%$ \\
\hline Concusion & 1 & $0.3 \%$ \\
\hline Cobro indebido & 1 & $2.4 \%$ \\
\hline Contra la administracion publica & 7 & \\
\hline
\end{tabular}

Fuente: MINJUS - Procuraduría Pública Especializada en Delitos de Corrupción (2020). 
Como se puede observar, en el Perú se evidencia que en estado de emergencia nacional la corrupción aumenta, que si bien es cierto la corrupción siempre ha existido en nuestro país, resulta preocupante y alarmante observar que en situaciones como en la que nos encontramos, donde la vida y la salud deben ser priorizadas sobre todas las cosas, existan funcionarios que se aprovechen de la crisis y la emergencia para lograr su beneficio personal aprovechándose de su cargo o el poder que puedan tener.

Figura 2. Porcentaje de casos de corrupción por tipo de delito al 27 de julio del 2020

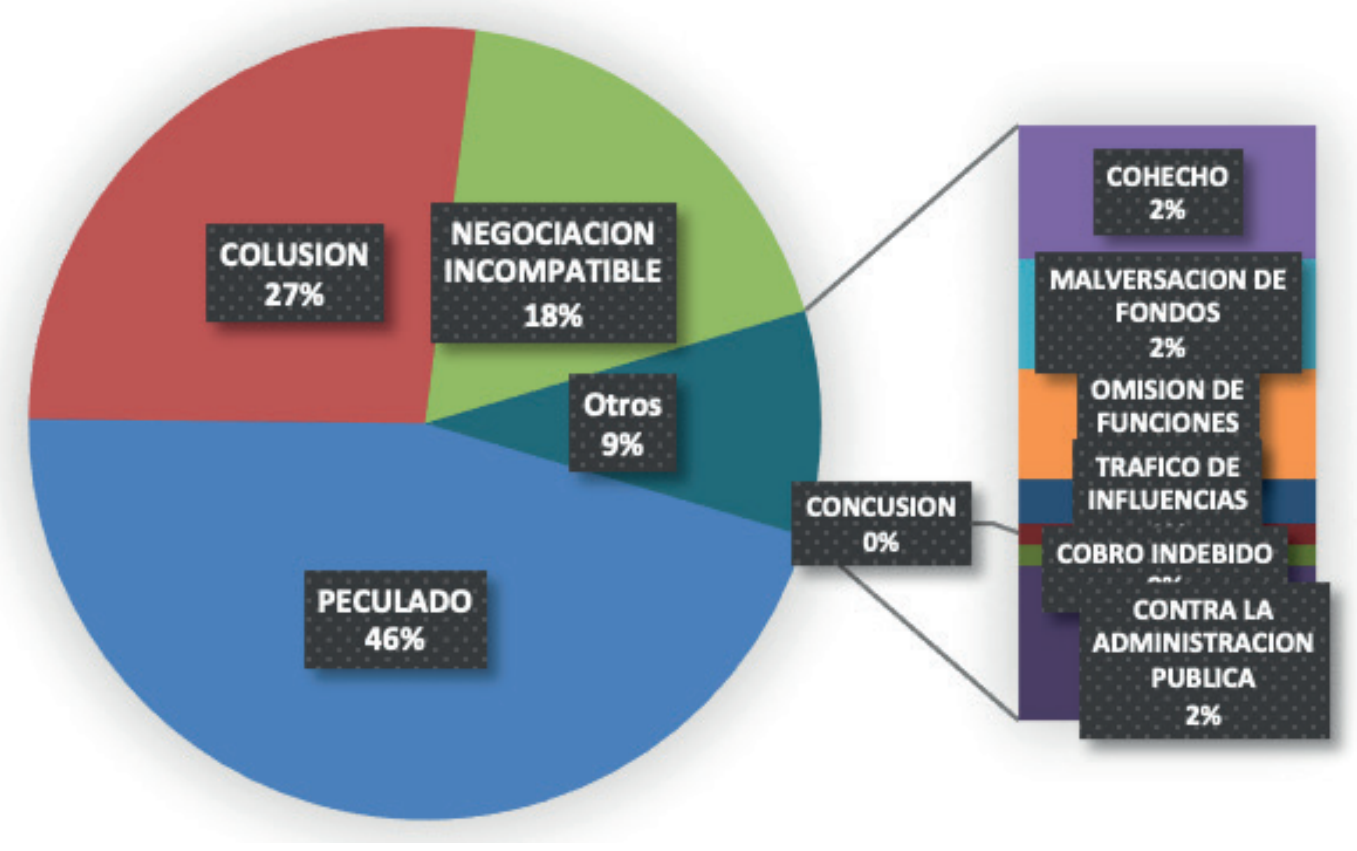

Fuente: MINJUS - Procuraduría Pública Especializada en Delitos de Corrupción (2020).

\section{Discusión y conclusiones}

1. Como se puede evidenciar los niveles de corrupción se han incrementado en el Perú durante el estado de emergencia nacional con más de 1186 casos que se originaron por presuntos actos de corrupción evidenciados durante esta crisis sanitaria, la misma que tiene como fuente los casos en trámite registrados, hasta el 27 de julio del 2020, en la Procuraduría Pública Especializada en Delitos de Corrupción nacionalmente que se encuentran participando activamente en defensa de los intereses del
Estado. Como se puede advertir, el $51 \%$ del total de casos se concentra en siete regiones, estas son: Ancash, Lima, Arequipa, La Libertad, Junín, Ayacucho y Cajamarca.

2. Es necesario la aplicación de mecanismos de lucha contra la corrupción como el compliance gubernamental que implica la simbiosis entre la ética pública y los elementos desarrollados en los programas de cumplimiento para el ámbito privado que pueden mitigar sustancialmente el riesgo de que se frustre la contención de la COVID-19 y de sus negativos efectos en los sectores vulnerables, al incidir en 
la prevención inmediata de la corrupción pública. Evidentemente, aquello no excluirá toda posibilidad de que se realice un acto corrupto, pero ayuda como acto disuasivo.

3. Es necesario que los funcionarios deben basarse en los valores fundamentales, como honradez, honestidad, fidelidad, justicia y respeto a la dignidad de la persona, entre otros, en los cuales se sustenta el cuerpo jurídico que regula la buena administración, centrados en la integridad, transparencia y responsabilidad, adoptados por los organismos del Estado que beneficien su reputación, en cumplimiento de programas anticorrupción.

4. La lucha contra la corrupción es un factor común a la mayoría de los países latinoamericanos. La ley debería ser muy dura en el castigo de casos de corrupción, más aún en épocas de pandemia, donde existe mucha necesidad, hambre y pobreza, donde se necesita una justa distribución de los recursos escasos, donde la vida y la salud deben ser priorizadas por sobre todas las cosas.

5. Esta crisis sanitaria se presenta como una segunda oportunidad para estrechar lazos con los excluidos del sistema, con los olvidados, esto puede ser una relación más cercana entre los países para propuestas de cooperación y colaboración mutua frente a la lucha contra la corrupción en tiempos de crisis. El Perú debe resolver con prontitud esta crisis, pero siempre cumpliendo con la ley, las responsabilidades públicas, el servicio, con el fin de cumplir con el interés general y el bien común, evitando generar actos de corrupción por acción, omisión o desconocimiento de sus autoridades.

\section{Referencias}

Albán, J. \& Poma, A. (2019). Problemática del sistema de control interno para erradicar la corrupción en el estado peruano. YACHAQ 1(2), 24-24. https://doi.org/10.46363/yachaq.v1i2.70

Albiac, M. D. (2001). La corrupción carcome Latinoamerica. Cambio 16, (1550), 48-50.

Arrieta, J. D. (2019). La adopción de buenas prácticas administrativas en los sectores público y privado como estrategia de prevención de actos de corrupción. Rev. Digital de Derecho Admin., 21, 429.

Artaza, O. (2019). Corrupción entre particulares: lesividad de la conducta y consecuencias en sede de tipificación de acuerdo al análisis comparado. Revista de derecho (Coquimbo), 26, 6. Epub 09 de octubre de 2019.https://dx.doi.org/10.22199/ issn.0718-9753-2019-0006

Begovic, B. (2005). Corrupción: conceptos, tipos,causas y consecuencias. Documentos Cadal. Centro para la apertura y el Desarrollo en América Latina 3 (26). https:// www.cadal.org/Documentos/documento_26.pdf

Cartolano, M. (2009). La corrupción, aproximación teórica. Bógota. Leyer, 20

Duque, J. D. (2020). Los principios de transparencia y publicidad como herramienta de lucha contra la corrupción en la contratación del Estado. Revista digital de derecho administrativo $N^{\circ} 024$ - Segundo Semestre, 79-101.

Frías-Aceituno, J. V., Rodríguez-Domínguez, L., \& García-Sánchez, I. M. (2014). Are directors also involved in policies against corruption and bribery in different corporate governance systems?. Revista Europea de Dirección y Economía de la Empresa, 23(1), 31-42

Gragera, J. \& Pascual, D. (2020). Corrupción en la democracia española. Una aproximación desde los aspectos criminales y políticos. URVIO Revista Latinoamericana de Estudios de Seguridad, (26), 105-122. https:// dx.doi.org/10.17141/urvio.26.2020.4131 
Julián, M., \& Bonavia, T. (2020). Psychological variables related to corruption: a systematic review.

Labaqui, I. (2017). Las causas de la corrupción: un estudio comparado. Colección, 14, 155-196, ISSN 1850-<https://erevistas. uca.edu.ar/index.php/COLEC/article/ view/738

Márquez, C. (2020). Clientelismo, patronazgo y corrupción en Colombia y México. Barranquilla: Universidad del Norte. Estudios Políticos, (57), 230-233. https://dx.doi. org/10.17533/udea.espo.n57a11

Madrid, C. \& Palomino, W. (2020). Oportunidades de corrupción y pandemia: el compliance gubernamental como un protector eficaz al interior de las organizaciones públicas. Revista de la Universidad Científica del Sur: Desde el Sur, 12(1), 213-239. https:// dx.doi.org/10.21142/des-1201-2020-0014

Mikhail, I. \& Walter, W. (2015). Corruption in the Mexican state bureaucracy. Revista de Economía Institucional, 17(33).

Ministerio de Justicia y Derechos Humanos [Perú]. Procuraduría General. Procuraduría Pública Especializada en Delitos de Corrupción. Boletín informativo 1: "Corrupción en la emergencia sanitaria COVID-19. https:// procuraduriaanticorrupcion.minjus.gob. pe/wp-content/uploads/2020/06/

Morales, M. (2009). Corruption and Democracy: Latin America in Comparative Perspective. Gestión y política pública, 18(2), 205252. Recuperado en 19 de septiembre de 2020, de http://www.scielo.org.mx/ scielo.php?script=sci_arttext\&pid=S140510792009000200001\&lng=es\&tlng=es.

Nieto, N. (2017). Enfoques y consecuencias de la corrupción. Iberoamérica 4. 63-84. https://www.iberoamericajournal.ru/sites/default/files/2017/4/nieto.pdf

Orellana, O. (2020). Pandemia Económica por COVID-19. Revista Científica Internacional, 3(1), 1-9. doi: https://doi.org/10.46734/revcientifica.v2i1.6

Orellana, J.C de.\& Velasco, J. A. (2019). Historia de la corrupción en el imperio español. Historia y MEMORIA, (19), 11-22. https:/doi. org/10.19053/20275137.n19.2019.9607.
Organización Mundial de la Salud - OMS (2020). COVID-19: cronología de la actuación de la OMS. https://www.who.int/es/newsroom/detail/27-04-2020-who-timeline--covid-19

Page, O. (2018). Corrupción institucional. Veritas. Revista de Filosofía y Teología, 9-19. Picon, C., Ramos, J.L., Almanza, C. y Ramos, J.L. (2020). Efecto conjunto de la democracia y libertad económica sobre la corrupción. Revista de Administração Pública, 54(2), 285-300. Epub May 15, 2020.https://doi. org/10.1590/0034-761220190165

Pérez, C.A. (2020). COVID-19 y corrupción: un análisis de la pandemia y la corrupción que socava el estado de derecho en México. Revista Académica de la Facultad de Derecho de la Universidad La Salle. https://repositorio.lasalle.mx/handle/lasalle/1694

Picon, C., Ramos, J.L., Almanza, C. y Ramos, J.L. (2020). The joint effect of democracy and economic freedom on corruption. Revista de Administração Pública, 54(2), 285-300. Epub May 15, 2020.https://doi. org/10.1590/0034-761220190165

Pastrana, A. (2019). Estudio sobre la corrupción en América Latina. Revista Mexicana de Opinión Pública, 13-40.

Quiroga, H. (2018). Ehe Factious State in Argentina.Corruption of Principles, Corruption of Institutions. Araucaria, 20(40). https:// revistascientificas.us.es/index.php/araucaria/article/view/6571

Quiroz, M. E. (2020). Desconfianza hacia la democracia en América Latina. Cuestiones constitucionales, 221-241.

Rodríguez Kauth, Á. (2011). Corrupción e impunidad: Dos estilos de cultura política latinoamericana. Investigación \& Desarrollo, 8(3).

Rojo, M., \& Bonilla, D. (2020). COVID-19: La necesidad de un cambio de paradigma económico y social. Ciencia América Vol.09 (2), 1-12.

Salinas, D. (2016). Proyecto Cerebro Humano:¿ Existen Experimentos Secretos Con $\mathrm{Hu}$ manos En Latinoamérica?. Archivos de Medicina (Manizales), 16(1), 192-198.Zuleta, A. P. (2015). La corrupción su historia 
y sus consecuencias en Colombia. http:// hdl.handle.net/10654/13973.

Vargas Ventura, J., \& Villa Incattito, P. (2020). ¿Cómo va la ejecución del presupuesto destinado para luchar contra el COVID-19
Yalle, O. (2020). Representación parlamentaria y corrupción en el Perú. el caso de los parlamentarios: 2011 - 2016. Scientia, 21(21), 99-116. https://doi.org/10.31381/scientia. v21i21.2762 